\title{
Context is king: Facilitation in innovation projects. A comparison between academic and industry projects
}

\author{
Reinhold Pabst \\ reinhold.pabst@iof.fraunhofer.de | Fraunhofer-Institute IOF, Albert-Einstein Str 7, 07745 Jena, \\ Germany \\ Isabelle Tyrasa \\ i.tyrasa@gmail.com | Fraunhofer IOF \\ Sebastian G.M. Händschke \\ sebastian.haendschke@iof.fraunhofer.de | Fraunhofer IOF, Friedrich Schiller University Jena, \& Bauhaus \\ University Weimar \\ Ralph Siepmann \\ ralph.siepmann@edcom.de | edcom Software \& Consulting GmbH \\ Antje Gonera \\ antje.gonera@nofima.no | Nofima
}

\begin{abstract}
Over the recent years, the importance of innovation in academic R\&D projects has increased. Nevertheless, innovation facilitation in the academic field has rarely been researched. Currently, innovation support focuses on the industrial context. In our study we aim to address this research gap and examine the facilitation of innovation in the academic and the industrial context. In our abductive empirical case study, we investigate the role, skills, mindset and instruments of innovation facilitators by interviewing 25 individuals from nine organizations. We discovered different behaviors and perspectives in dealing with innovation work, depending on the context of the either academic or industry-driven projects. Academic innovation projects focus on feasibility, whereas industry-driven projects focus on viability. In both contexts, the facilitators usually intend to include the user perspective (desirability). With our results we contribute to the facilitation literature and show that innovation projects and their facilitation depend on their specific context and the mentality of the facilitators. With these results, we strive to improve academic and industry-driven projects with advice for innovation practitioners and facilitators on helpful tools and important perspectives to fully exploit the innovation potential.
\end{abstract}

Keywords. Open Innovation; Innovation Process Facilitation; Innovation Projects; Project Setup Stage; Facilitation Perspectives; Academia-Industry Comparison.

Cite paper as: Pabst, R., Tyrasa, I., Händschke, S., Siepmann, R., Gonera, A., (2020). Context is king: Facilitation in innovation projects. A comparison between academic and industry projects, Journal of Innovation Management, www.open-jim.org, 8(3), 48-74. 


\section{Introduction}

Innovation is a central component of economic growth. In the industrial context, there are a large number of innovation management tools and systems for product development, radical innovation, user-centered innovation, among others (Tidd \& Bessant, 2014). Traditionally, innovation development in the academic context is not handled in such a formalized way. Academic R\&D tends to focus on academic merit and peer recognition (Simons, Gupta \& Buchanan, 2011). However, a major change is taking place in academic research projects.: Knowledge creation is no longer the sole objective of such projects in the academic field. Public calls for research projects increasingly address complex societal challenges that can only be solved by transdisciplinary teams and in cooperation between industry and academia with a strong focus on innovation and implementation (European Commission, 2018a; Popowitz \& Dorgelo, 2018). This requires new roles and new skills in innovation work.

Facilitation of innovation processes is an important topic for current innovation literature (Johnsson 2017, 2018; Klerkx, Álvarez \& Campusano, 2014). Facilitators are seen as process facilitators and neutral coaches (Klerkx et al., 2014) who enable project teams to focus on their progress and thus work more effectively and efficiently in the different phases of an innovation project. Not only the innovation process, but also the cooperation of different functions and disciplines must be facilitated in order to bring the different disciplines together (Thompson, Owen, Lindsay, Leonard, \& Cronin, 2017).

Different phases of an innovation project require different innovation support, tools and skills. Gonera and Pabst (2019) as well as Johnsson (2018) point out that the set-up phase of innovation projects is crucial for the formation of effective project teams. The objectives in this initial phase are to create a common understanding of the innovation team in relation to the challenge and to consciously address the different roles and responsibilities (Johnsson, 2017). Building a common language is particularly important as innovation teams usually consist of different disciplines and in some cases even different organizations. Since new solutions to a new or existing problem are the goal of an innovation project, the requirements and constraints of the solution must be clearly defined for all team members. Developing a common view of the requirements is one of the first tasks of a facilitator (Kolb et al., 2008).

Studies on the facilitation of innovation were primarily carried out in an industrial context, while the academic sector remained invisible to most researchers (Todeva, 2013). Previous research has been limited to studies on intermediaries and governance (Todeva, 2013) and studies on knowledge transfer between academia and industry (Hermans \& Castiaux, 2007; Ii et al., 2018). This indicates a need for research on facilitation in the academic environment. At the same time, the facilitation of innovation in academically driven projects is becoming increasingly important (Mazzucato, 2018). The pressure to exploit research results is increasing, combined with the expectation to solve complex societal challenges that lead to results with a high impact (ibid.).

We find a different innovation logic in academic innovation projects than in industrial projects. The academic logic concentrates on the generation of research-based knowledge and academic merit, whereas the transfer logic of innovation projects in industry focuses on the translation 
of research results into new applicable projects or even marketable products. We ask ourselves whether academic innovation projects need a different approach to facilitation due to the different innovation logics?

Since little is known about the role of facilitation in the academic context, this research aims to understand if and how the two different organizational contexts influence facilitation. In other words, this paper consists of two main components: Our research focus is on the "role of context" in relation to the "role of facilitation" in an innovation project. With our abductive empirical case study we aspire to learn more about the context-specific understanding and implementation of facilitation and its embeddedness through the following research questions:

RQ1: What role does facilitation of innovation projects play in academic contexts compared to industrial projects?

RQ2: How does the context influence the innovation focus in the respective organizations?

The aim of the paper is to sharpen the perspective for the different viewpoints for innovation depending on the context of the innovation project - academia or industry. We achieve this by investigating the innovation facilitators' tasks, skillset, mindset, and toolset in academic innovation project setups in comparison with similar industry examples by interviewing 25 individuals of nine organizations in the two contexts.

\section{Theoretical background}

\subsection{Context is king: Academically and industry driven projects}

Academically driven innovation projects need public funding that is historically based on academic excellence and has a success rate of only 12\% (European Commission, 2018b). According to Besterfield et al (2008), the focus in academic innovation contexts is primarily on technology development. Non-technical issues relating to strategy or society, as well as financial, human and competitive aspects receive less attention in academic innovation projects than in industrial projects (ibid.).

According to Simons et al (2011), the main difference between industry-led and academic innovation projects lies in the different focus. Industry-led innovation projects focus on company productivity and the creation of customer value. Academic innovation projects, on the other hand, focus on personal productivity, the search for knowledge and the building of reputation among like-minded people (ibid.). Gonera \& Pabst (2019) describe the innovation process in academically managed projects as incomplete at both ends. At the first end, the beginning of the project, user needs are hesitantly included in the innovation process. At the end of the project, academic projects often have little interest in market commercialization (ibid.). Further, publicly funded innovation projects are relatively rigid in their execution. A priori, a linear process with predefined activities, fixed milestones and little room for iterations is usually established. 12 to 18 months before the actual start of the project, the pre-project phase begins, in which a project application bound to specific funding guidelines is formulated. The application process 
usually leaves little room for exploration of the problem area and creative processes due to short deadlines and high workload of the applicants (Nicholson \& Ioannidis, 2012).

In contrast, industry-driven innovation projects are more strategically oriented. They focus on user needs and aim to increase company productivity and value creation. The design and management of innovation projects can be much more diverse and agile. Depending on the innovation management practices and tools a company applies to solve a problem, the scope of innovation varies from incremental to radical. Innovation projects can relate to products, processes, positioning and paradigm innovation (Francis \& Bessant, 2005).

Industrial innovation projects can have different project durations. They are usually shorter than academic research innovation projects, as they do not receive public funding and focus more on a short time-to-market to maintain a competitive advantage.

Dong et al. (2017) compare the two contexts and note that the results of academic innovation projects are often less commercially oriented, and the results are more difficult to absorb for private sector partners. Furthermore, innovation facilitation is much less established in the academic world than in industry. However, there are developments to facilitate innovation in academic projects, including research and innovation cooperation between academia and industry (Gonera \& Pabst, 2019), on which we build in our study.

\subsection{Facilitators and facilitation in innovation}

According to Johnsson (2018), the main task of an innovation facilitator is to support innovation teams in carrying out their innovation work. Moderation in innovation projects can be understood in different ways. It can either be used as a fixed strategic process with specific practices (Brunswicker \& Vanhaverbeke, 2015), e.g. in the form of borderline objects (Djelassi \& Decoopman, 2016) or in some cases as practices that a (project) leader should take over (Hunter \& Cushenbery, 2011) or as a dedicated role. In the literature on innovation management, the mediating role is most frequently found (Price, Wrigley \& Matthews, 2018). This role can be independent or an extension to another role, such as the role of the project leader (Anantatmula, 2010). However, both roles, that of facilitator and that of project leader, are very demanding in themselves. This is especially true for interdisciplinary cooperation in joint projects with partners from industry and science (Bartunek et al., 2007; Beloniel \& Somech, 2015; Klerkx et al., 2014; Salazar et al., 2012). Those who assume the moderation function are usually referred to in the literature as facilitators. Generally, a facilitator can be defined as someone who drives the (innovation) process and integrates the different project partners into the project group (Ollila \& Yström, 2017). Konsti-Laakso, Pihkala and Kraus (2012) note that facilitators can be outsiders of the department or even the organization (i.e. a consultant). However, according to Nelson and McFadzean (1998), facilitators can also be part of the group. Benefits in terms of trust among project members, workload, and knowledge of processes and organizational peculiarities are inherent, but outsiders can also offer new perspectives. 


\subsection{Skillset, mindset, toolset of a facilitator}

There is no fixed definition of the tasks of facilitation. The understanding of facilitation in our paper is based on Kolb et al. (2008), who focuses on the neutral facilitation of group discussions and processes. The aim is to promote a fruitful group dialogue and to use tools and methods to improve group interaction and performance. Davis and Eisenhardt (2011) stress the importance of achieving common goals and clarifying the perspectives and interests of the individual partners as well as mobilizing different people with different levels of knowledge according to the project phase. In addition, emotional aspects such as promoting a positive group experience and motivating the group members (Kolb, Jin \& Song, 2008) or networking (Konsti-Laakso, Pihkala \& Kraus, 2012) are part of the tasks of a facilitator. In either case, some form of training or other forms of learning might be necessary to understand what is expected of the facilitator in terms of his or her purpose and self-image (mindset) and the skills and tools required (Nelson \& McFadzean 1998).

Johnsson (2018) identified 40 characteristics of an innovation facilitator and demonstrated their importance in the different phases of the innovation process. The characteristics are mainly limited to the skills and mindset and there is no clear description of which tools are needed in which phase. Several design thinking scientists and practitioners as well as management consultants apply the framework of skillset, mindset and toolset in the innovation context (Nelson \& McFadzean, 1998; Horth, 2012; Howard et al., 2015; Brenner, et al., 2016; Autodesk, 2017; StudioScience, 2017). We apply this framework for studying the facilitation role.

The skillset of a facilitator is a framework that enables them to use knowledge and skills to achieve their goals. More than tools and techniques, it requires the ability, practice and mastery of processes. The facilitator needs the skills to deal with complex situations and contents as well as interpersonal aspects (Bozik, 2016). Other examples of facilitation skills are technical and rational skills, competencies, context understanding approaches for creative problem solving and good time management.

The mindset is the individual perspective. It determines how a person approaches and interacts with the world (Nelson and Stolterman, 2003). It encompasses the values, attitudes and resulting behaviors that enable the tools and skills to take effect. Examples of the mindset of an innovation facilitator are characteristics such as curiosity, tolerance of ambiguity, reflexivity and customer orientation. Customer-centricity in particular indicates the desirability of innovation as the goal of a facilitation process, which leads to the triangle of feasibility, viability and desirability of innovation projects (Brown, 2009).

The toolset is a collection of tools and techniques for generating new options and implementing them in an organization. Examples of tools are: Prototyping, Brainstorming, Mind Mapping, Ethnography or Design Thinking (Curedale, 2019). In short, the tools support the creation and implementation of innovation efforts. 


\section{Method}

\subsection{Research approach}

In this paper we aim to examine facilitation in innovation projects in both the academic and industrial context. We conducted an empirical abductive qualitative study with 25 interviews with facilitators from industrial and academic contexts. More specifically, we use an explorative approach based on qualitative case studies (Eisenhardt, 1989; Yin, 2017). Integrated case studies assume that there are both similarities and differences in the different cases that can explain causal questions. We apply a multiple case design and compare two different contexts, namely industry and academic innovation projects, with individual facilitators and their projects as an embedded unit of analysis (Yin, 2017). We structured the interviews according to how facilitators work in the two different organizational worlds, along the lines of how they think (mindset) and how they work (skillset) and what tools they use (toolset).

\subsection{Sample and research context}

In this empirical study, we conducted 25 interviews with facilitators from nine different organizations in Central and Northern Europe. In the academic context we interviewed facilitators from three research institutes and one university. In the industrial context we interviewed facilitators from five different companies.

In the academic context, all research institutes and the university work together with partners from the private sector. Their innovation projects are mainly defined as services for their industrial partners and they work in close cooperation with them. The interviewed academic facilitators work in the public sector and must follow strict rules and regulations since they are accountable to their respective funding bodies. On the other hand, industry-led projects do not have the same dependencies from funding bodies but mainly focus their innovation projects on a marketable product, as the existence of companies/their company depends on it.

All organizations work on highly specialized and research-intensive topics. In addition to this, they are all large enough to invest in projects that involve both innovation and facilitation efforts, so that it is possible to learn from them. The projects are called "innovation projects" but some organizations used different names, such as "research projects" (Research Institute F) or "acceleration projects" (Corporation I). We selected the companies based on the idea that they come from very different sectors in order to allow for a better comparison. The companies are active in the same sectors as the academic institutions: infrastructure, high technology, consulting and food. ${ }^{1}$

$1 \quad$ An exchange between the industry and academic authors of this paper was also the origin of this study and helped to understand the context factors better and be able to follow the explanations more easily. 


\subsection{Data Collection}

Our interview material consists of 25 semi-structured interviews. We collected 10 interviews between January 2019 and May 2019 and, after analyzing the initial data, conducted another 15 interviews between December 2019 and February 2020. The interviewees are facilitators who perform moderating tasks in innovation projects in academic and industrial contexts. All interviewees perform these process-supporting functions in current innovation projects. The interviewees are equipped with experience in facilitation as well as expert knowledge in a specific discipline and possess experience with innovation projects and their processes. We included each expert interview in this study, after transcribing and analyzing it sequentially.

The respondents from industry and academia were asked the same questions related to their organization and their context. They did not receive the interview guide or other additional information prior to the interview. During most of the interviews, both the interviewer and another researcher were present. This allowed a researcher to take notes of interesting observations during the interview and in some cases to discreetly ask the interviewer to raise the subject again for further details. Thus, we also received detailed field notes that we used for data analysis. The researchers found it particularly valuable to obtain a shared perspective on the responses immediately after the interview was completed. This promoted the development of a common understanding within the research group.

In the interview guideline, we avoided using explicit labels and asked the respondents general questions about their role in innovation projects. This allowed the respondents to self-identify their role, tasks and projects. Each interview included questions about the role of the respondents, project development and the project structure.

We adapted some questions according to our experiences from the first interviews. We found that the context seemed to be of crucial importance and that it was easier for the interviewees to talk about certain exemplary projects. Consequently, we started to ask about the context and these projects and then proceeded to ask certain open questions, such as clarifying statements or aspects of interest that they did not mention (in detail).

After interviewing nine industry facilitators and 16 academic facilitators, we reached a saturation point where we did not receive any further substantial information from the respondents, and we completed the data collection.

We extensively collected additional material related to facilitation from the interviewed organizations. The additional information material sent to us by some of the interviewees after the interview was particularly valuable for us. In this way, we were able to gain a deeper and more comprehensive understanding of how innovation processes are facilitated

\subsection{Data Analysis}

With the objective of obtaining a very comprehensive understanding of facilitation in its various contexts, we have used the Gioia method (Gioia et al., 2012) as a qualitative interpretation method to obtain more empirical rigor and visualize the data structure. We alternated between theory development,research question and our guiding assumption, constantly comparing our 
Table 1. Overview of case companies and interviewees

\begin{tabular}{|c|c|c|c|c|}
\hline No & Company & Country & Sector & Interviewees \\
\hline 1 & Corporation D1 & $\begin{array}{l}\text { International / } \\
\text { Germany }\end{array}$ & Digital & $\begin{array}{l}\text { 1: Project Manager } \\
\text { 2: Head of Innovation } \\
\text { 3, 4: Innovation Coach } \\
\text { 6,: CEO and Innovation } \\
\text { Manager }\end{array}$ \\
\hline 2 & Corporation D2 & $\begin{array}{l}\text { International / } \\
\text { Germany }\end{array}$ & Digital & Interview 5 \\
\hline 3 & Corporation D3 & $\begin{array}{l}\text { International / } \\
\text { Germany }\end{array}$ & Digital & Interview 7 \\
\hline 4 & Corporation I & Germany & Infrastructure & 1, 2: Innovation Manager \\
\hline 5 & Corporation F & Norway & Food & 1: Project Manager \\
\hline 6 & $\begin{array}{l}\text { Research } \\
\text { Institute P }\end{array}$ & Germany & $\begin{array}{l}\text { Physics / } \\
\text { Technology }\end{array}$ & $\begin{array}{l}\text { 1: Innovation Manager } \\
\text { 2, 4, 5: Project Coordinator } \\
\text { 3: Education and Innovation } \\
\text { Manager }\end{array}$ \\
\hline 7 & $\begin{array}{l}\text { Research } \\
\text { Institute B }\end{array}$ & Germany & $\begin{array}{l}\text { Economy, } \\
\text { Business } \\
\text { Administration }\end{array}$ & $\begin{array}{l}\text { 1: Innovation Manager } \\
\text { 2: Project Manager } \\
\text { 3, 4: Project Manager, } \\
\text { Middle Management }\end{array}$ \\
\hline 8 & $\begin{array}{l}\text { Research } \\
\text { Institute F }\end{array}$ & Norway & Food & $\begin{array}{l}\text { 1-5: Researcher and Project } \\
\text { Manager }\end{array}$ \\
\hline 9 & University E & Finland & Education & 1: Innovation Manager \\
\hline
\end{tabular}

data within and between cases. This allowed us to incorporate our previous knowledge from literature and other studies, but also to gain new insights to identify the aggregated dimensions that drive facilitation. The interviews were anonymized and exchanged among the first two authors for mutual analysis. We also used memos for our internal communication.

Each interview was analyzed before the next one was conducted. Between the interviews, we began to develop second-order concepts, which were derived from the first-order concepts by inductive coding of the interview transcripts. The interview protocols were divided into two groups: academic and industrial cases. This was done after the first round of interviews (January to May 2019). We were able to design our questions in the following interviews in such a way that we could get a more comprehensive picture of the cases. The analysis was conducted within the cases and across cases according to Yin (2017). From the secondary material and interview notes, various topics related to the facilitators' skills, mindset and instruments were 
derived, which were then bundled and further refined. A summary of each case was written to complement the aggregated data and allow for cross-case comparison. The analysis was iterative, and the summarized topics and results were discussed between the researchers in the group until we agreed on each concept before jointly developing the dimensions. From the $2^{\text {nd }}$ order concepts we developed two relevant dimensions: The context factors and the facilitation role (see Fig. 1. Overview of the coding process). These two dimensions serve to compare facilitation processes, structures and resources and to explain the differences between industrial and academic innovation project settings.

We have developed the following conceptual model from the data structure. It shows what influence the context of an innovation project has on the success of an innovation and how it stimulates the learning process of facilitation. The facilitation is influenced by the personal resources of a facilitator.

\section{Results}

\subsection{Summary of findings}

The results suggest that there are differences in facilitation between industry and academically led innovation projects. The context influences the facilitation process, the facilitation approach and the facilitation goals. Interestingly, the three digital companies showed a similar attitude towards facilitation and innovation projects, which helped to compare them more easily with other sectors. A within case comparison showed that the facilitation efforts differed more between the companies than between the research institutes while the biggest difference was seen between the different cases (industry and academia). While some companies had a specific facilitation role, digital companies adopted a fixed, structured approach to facilitation practices. The facilitator role in academically led projects is not well established and facilitators often have a personal motivation to take on that role rather than an established organizational structure or official mandate.

\subsection{Project settings}

Table 2 shows a comparison of the principle contextual differences of innovation projects in industry and academia.

Academic institutions are still organized predominantly hierarchically and are financed by public funds. This often means long waiting periods between project planning and project start. Only after the financial project funds the institutions applied for have been granted, the projects can be filled with staff positions. In the case of academically driven innovation projects, the applicants already have feasibility aspects and, in particular, technological aspects in mind during the early stages of an innovation project. According to the very formalized project management, the requirements of the funding agencies result in a milestone-driven reporting obligation.

"They [the funding body] monitor whether we complied with the roadmap and the work pac- 

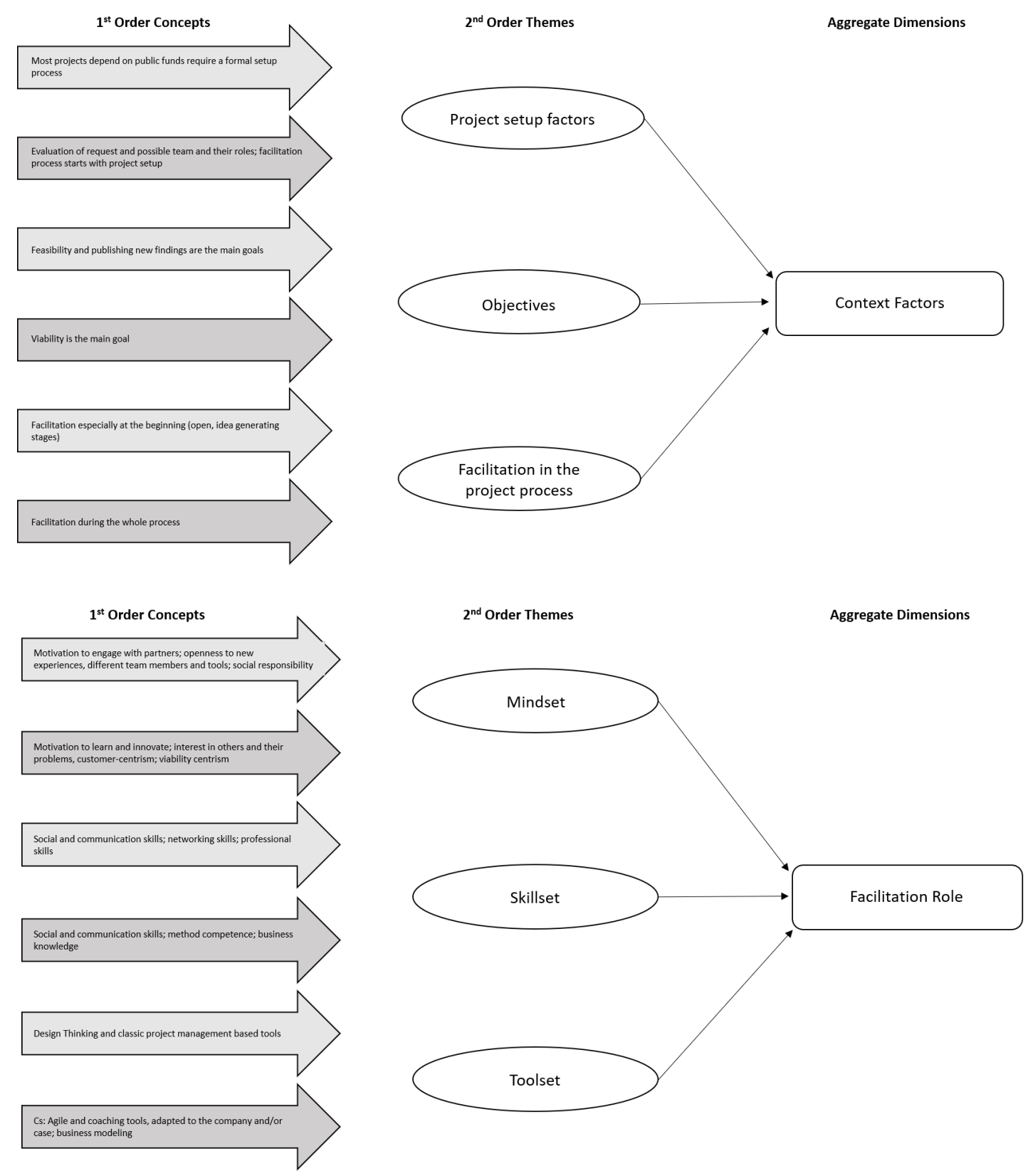

Fig. 1. Overview of the coding process and identified concepts

kages. They also want to see if we can reach the objectives from the application" (interview 4, Research Institute P).

In contrast to the academic innovation context in our sample, the five companies seem to have more agile systems for facilitating innovation. Facilitators in the industry context indicated that the projects are less formalized and more individualized in terms of their roles and the project process: 


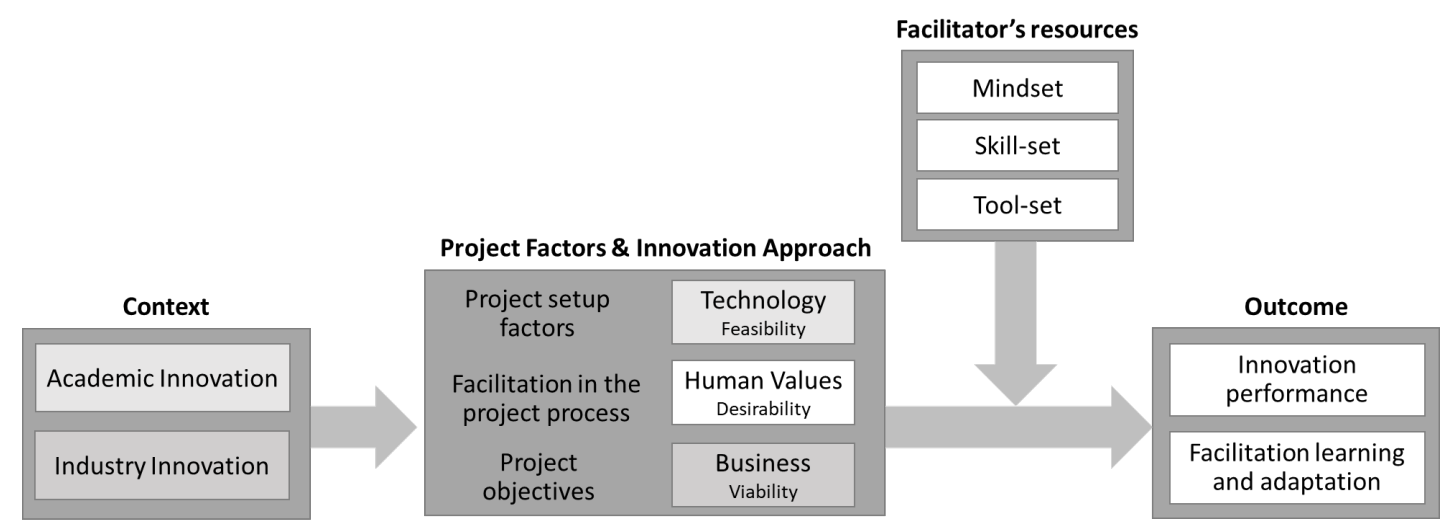

Fig. 2. Conceptual model

"Each project is different in its implementation. Sometimes I am involved in facilitation from start to finish, sometimes only during a certain phase. My role is also always different" (interview 2, Corporation I).

However, the decision process for or against a project and the whole process seems to be very specific and based on clear objectives such as KPIs, especially in digital enterprises:

"What is important, everyone pitches, when they go to the investment committee. Pitches the idea but also needs to include the needed funding. As a startup, you need to say how much money you are going to need the next 12 to 15 months more or less in order to initially validate the idea, and also with which KPI you want to be evaluated." (interview 5 , Corporation D2).

\subsection{Facilitation mindset, toolset, and skillset}

Throughout the research process, we found that the focus of innovation at the beginning of innovation projects varies depending on the context. We found that funders of academically

Table 2. Overview of the project settings in industry-driven and academia-driven projects

\begin{tabular}{ll} 
Industry-driven projects & Academia-driven projects \\
\hline $\begin{array}{l}\text { Private funding: Focus on viable product } \\
\text { development and speed to market }\end{array}$ & $\begin{array}{l}\text { Public funding: Focus on feasibility and } \\
\text { academic success, product development } \\
\text { commercialization is not intended }\end{array}$ \\
$\begin{array}{l}\text { Flexible team composition, agile innovation } \\
\text { process, frequent and KPI-oriented control } \\
\text { points by the management throughout the } \\
\text { innovation process }\end{array}$ & $\begin{array}{l}\text { Long project application stage, fixed } \\
\text { partners, administrative burden (compliance } \\
\text { with the original application), linear project } \\
\text { set-up }\end{array}$ \\
\end{tabular}


Table 3. Overview of the facilitation mindset, skillset, and toolset

\begin{tabular}{cll} 
& Facilitators in industry projects & Facilitators in academic projects \\
\hline Mindset & $\begin{array}{l}\text { User centricity and viability } \\
\text { orientation }\end{array}$ & User centricity and feasibility orientation \\
Skillset & $\begin{array}{l}\text { Social skills, innovation method } \\
\text { skills, business skills }\end{array}$ & $\begin{array}{l}\text { Social skills, innovation method skills, } \\
\text { professional and scientific expertise }\end{array}$ \\
Toolset & $\begin{array}{l}\text { Agile tools adapted to } \\
\text { management practices and } \\
\text { marketability issues }\end{array}$ & $\begin{array}{l}\text { Agile or project management tools with a } \\
\text { focus on desirability and product } \\
\text { development }\end{array}$ \\
\hline
\end{tabular}

driven projects have a feasibility-driven mindset, while funders of industrially driven projects have a more viability-driven mindset.

Innovation facilitation is practiced in all academic institutions. However, the role descriptions of the facilitators differ. All but three respondents from Research Institute P describe that their researchers have a dual role:

"I have to do both jobs, being a researcher and facilitating the process" (interview 1, Research Institute F).

All academic institutions understood facilitation as a role to build innovation competency within the team and support for an agile and user-centered approach:

"That means that on the one hand, I explain innovation to my researcher colleagues, who are often not familiar with the terminology of innovation. On the other hand, I facilitate practical innovation tasks, such as idea brainstorming, user needs, customer journey, often in a workshop format." (interview 1, Research Institute F).

In addition to this, the interviewees from academia perceive themselves as a translator between the different stakeholders from the public, private and academic sectors:

"[My tasks are] innovation activities, to act as a translator between the different actors from the research and academic environment and the business environment" (interview 1, Research Institute F).

According to all academic interviewees, the art of facilitation includes fostering the active involvement of the actors from different disciplines within the projects:

"So, in my team, I try to support people in taking ownership of their own expertise. Saying like you do not need to become an engineer and you do not need to understand everything. And just ask questions [of what you do not understand], you are now an expert in your own field and this is what you bring to the team" (interview 1, University E).

The subsequently required academic facilitation mindset includes openness and interest towards others, a "people-first" mindset and compassion:

"You need to work with all kinds of people. Oftentimes, people from lower positions have the 
information you need. As a researcher, you should never underestimate people" (interview 2, Research Institute F).

Apart from interpersonal skills, facilitators from Research Institute $\mathrm{F}$ also stress the importance of networking and hosting. Research Institute $\mathrm{P}$ also mentions personal and process-related skills such as self-organization. All corporations, similar to the academic institutions, consider social and communication skills as very important:

"The handling of people, the work with people, you need to be able to think of solutions. I cannot really describe the concrete characteristic, but you just need to have knack for call attention to issues diplomatically. Like a mix of empathy, communication and problemsolving" (interview 4, Corporation D1).

The facilitators from the Research Institute F require a professionally relevant academic background:

"You need to have expertise knowledge in our sector, as you need credibility in the area you are working in" (interview 1, Research Institute F).

The understanding of the facilitator role and mindset differs even more among the different corporations. In contrast to mixing content-related and facilitating roles freely, processes in the corporations from the digital sector are highly formalized with strict roles and processes, some of them similar to scrum and process concepts derived from Design Thinking:

"We introduced our own flavor of Design Thinking. We did this company-wide. I believe that almost fifty percent of the corporation employees have already completed a web-based training" (interview 1, Corporation D1).

Whereas the digital corporations do not appear particularly interested in a facilitator role, interviewees from Corporation $\mathrm{F}$ as well as Corporation I state the need to have a specific person in the room who facilitates the innovation work and integrates the different team members:

"You need people to understand business potential, you need people who understand the technology and you need people who are good at understanding users. And then you need people who understand how these three perspectives can work together" (interview 1, Corporation $\mathrm{F})$.

Especially Corporation I uses a variety of different tools, adapting it to the individual project. Both interviewees from this corporation even questioned the importance of job descriptions and fixed roles. They indicated that they offer a broad field of support regarding team building, market and user research and analysis, as well as administration and mentoring:

"It is always different, but the essence of my role is to find out what the real problem is, how to solve it and with which methods and which scope it has. There are different roles I play, from the first interview to the follow-up and settlements" (interview 1, Corporation I).

All interviewees share that all corporations use a user-centered and especially customer-centered approach and try to provide their teams with a lot of liberty and with equal voices in decisions. 
The mindset for agile projects in all corporations includes, similar to the academic institutions, the openness to learn and innovate as well as the interest in the stakeholders and their issues:

"A lot of the innovation efforts are only celebrated if they are launched into the market, but instead, it is important to celebrate if we learn something is unviable, or we should not do this is something we actually learned." (interview 1, Corporation F).

The viability orientation can also be perceived as part of the corporate facilitation mindset.

Regarding the expected skillset, all academic institutions favor communication and interpersonal skills:

"[You need] trust, access and the ability to communicate both ways" (interview 4, Research Institute F).

All corporations expect these social and communication skills. Apart from this, Corporation I also stressed the importance of some method skills as well as business and market knowledge.

Most academic facilitators use agile innovation tools, which in most cases are inspired by Design Thinking. However, one interviewee from Institute $\mathrm{P}$ admits that his project team still uses non-agile project management tools:

"In my team, we still use the old waterfall project scheme." (interview 2, Research Institute $\mathrm{P})$.

According to the corporate interviewees, all corporations use agile tools. However, in digitally operating corporations, the tools appear much more fixed than in the other Corporations:

"That was the reason why we had a look at Design Thinking and said, how can we expand this so it can work in such a global, big corporation with project teams consisting of hundreds of people. Then we added the management practices." (interview 1, Corporation D1).

Interviewees from the other corporations stressed their wish for agile methods, but did not have a fixed set of tools they use:

"We are very need-oriented, you take something out from a big toolbox. We have some things from Design Thinking, UX Design, Business Consultancy, Lean Startup, User Journey, Design Dash, Liberating Structures and many more" (interview 1, Corporation I).

Apart from the use of an adapted Design Thinking approach, all three digital corporations also use some sort of Business Model Canvas:

"We proceed mostly by using Business Model Development 85 Innovation (BMDI) (Osterwalderspecific), Business Model Design, and we also use tools such as the Value Proposition Canvas, Network View" (interview 5, Corporation D2). 
Table 4. Overview of project phase-specific characteristics of facilitation

\begin{tabular}{lll} 
& Industry-driven projects & Academia-driven projects \\
\hline $\begin{array}{l}\text { Facilitation } \\
\text { start }\end{array}$ & $\begin{array}{l}\text { After project set-up and } \\
\text { acceptance }\end{array}$ & Pre-project set-up \\
Facilitation activities & $\begin{array}{l}\text { During the whole process or } \\
\text { during a specified part of the } \\
\text { process }\end{array}$ & $\begin{array}{l}\text { Especially during the pre-project } \\
\text { stage, the project set-up stage and } \\
\text { during open, idea searching phases }\end{array}$ \\
Facilitation objectives & Mainly viability & Mainly feasibility \\
\hline
\end{tabular}

\subsection{Innovation project phase}

We found a context-dependent variation of when and how innovation facilitation is carried out as shown in table 4 .

Prior to research and innovation project set-up, academic facilitators need to develop the scope of the research, identify and convince potential partners and write detailed proposals since most projects depend on public funds:

"In our role as a research institute we have to apply for public funding. The application process can go on for a long time depending on the (public) sponsor" (interview 1, Research Institute P).

Regarding the process-related facilitation tasks, all but one interviewee from academic institutions stated that the facilitation starts at the pre-project stage and continues into the project set-up stage. This means that they start facilitating before the first project tasks start. Many even concluded that their presence is most essential in this project phase:

"[At this stage] we are building in the language and the thought of innovation. I'm offering to be a close collaboration partner to the project leader at that [set-up and starting] stage in defining not only the project scope, but also the way we will work with innovation in the project." (interview 1, Research Institute F).

The detailed proposals also complicate pivoting and pose a restriction to agile project management.

In corporations, facilitation usually starts later. First, some sort of board or management decides whether a project will be started. This is based on the potential of the business idea and whether there is a suitable and willing team with the necessary qualities to develop a solution:

"[You need a] diverse team-composition with experience on market fit, architects, developers and researchers" (interview 2, Corporation D1).

Building a team is an important facilitation task in corporations as well. While interviewees from corporations in the digital field mostly refer to the team composition (i.e. deciding who needs to be part of the team. The decision process in favor or against an idea, presented by a team, is less formal, but very thorough in all corporations. 
Facilitators from all academic institutions indicated that they are present in processes from the setup stage until the project end. Due to anti subsidies rules and a strong research focus, they usually do not participate in the implementation of a new product and are not responsible for it:

"We are present during the project period, but not the transfer of project results. The implementation of the innovation is not done in the project period, it is ideally taken over by the industry partners" (interview 1, Research Institute F).

However, facilitators from Research Institutes P, F and the University E indicated that they are using their facilitation techniques mostly in open and diverging stages like idea-generation, workshops and networking stages.

Project processes in all corporations are similarly structured to the Design Thinking process with iterative research and a learning process:

"So, I believe it is important that all processes in innovation look circular, but it is important to also note that when you are, for example, when I am working to struck up a new way with innovation canvas, it is important that we put learning in the center and not the consumer." (interview 1, Corporation F).

Facilitators of all three corporations, just like the facilitators from the academic institutions, stated that in most cases the process ends before the implementation of the innovative idea. However, the innovative idea is, in most cases, implemented within or in cooperation with their corporation:

"We make sure that there is some kind of handing [the product or service] over to the standard machinery or the standard commercialization process and, that way, becoming part of the pricing list. And then, we generally leave" (interview 5, Corporation D2).

Regarding the academic institutions' objectives, one interviewee from Research Institute F mentioned a triangle of resources and interests with the end user being a central focus. Still, academia driven projects are mostly focused on the feasibility of a project:

"There is a triangle between us, the companies and the technology provider. The end user can tell us about all the requirements and also about the process and then I know what is possible to do as a researcher and the technology provider can be an acting part and try to adjust or develop an instrument that is perfect for this particular application [which the company needs]". (interview 4, Research Institute F).

Neither the research institutes, nor the universities focus on the question, whether you can gain profit from the innovation:

"Viability, I do not know, since we are operating in a semi-public area, this is something we would need to test. The next step should be to really go into the market or, well, do it with an internal cost allocation in our organization. But actually, we do not really plan this. In fact, we would like to provide [this service] for free, to penetrate a higher segment." (interview 2, Research Institute B). 
Viability, however, is a vital factor for all corporations:

"We believe that Design Thinking alone is not sufficient since we found that you often get ideas that lack viability. When you do classical Design Thinking, there is more [of a focus on] desirability and feasibility, which in the end is also part [of the end product], that you obviously consider the users more in Design Thinking and pay less attention to the Buying Center." (interview 5, Corporation D2).

The question, whether something is viable, i.e. profitable for the corporation, is a decisive criterion for the start und continuation of an innovation project at all stages.

Another result we found was that if an innovation facilitator performed well, they become obsolete. This appears to be the reason why facilitators from both the public and the private sector were mostly active during the early project phases. Also, some corporations even teach the employees facilitation mindsets, tools and skills to be independent from a facilitator role, as one interviewee from a corporation in the digital field stated:

"We are not interested in the role of a facilitator anymore, since facilitation is not sufficient to make teams successful" (interview 1, Corporation D1).

\section{Discussion}

With our study, we contribute to contextualize the phenomenon of facilitation in academically led innovation projects. This opens an emerging area of research driven by the changing requirements for publicly funded projects to deliver not only knowledge but also innovations. The mindsets that dominate the academic and industry sector lead to distinct objectives and orientations. The most notable differences that emerge from these mindsets are the distinct main objectives and orientations of innovation projects. This adds to Brown's innovation framework (2009) where the sweet spot of innovation includes desirability, viability and feasibility. Innovation projects may actually just favor one or two of these aspects due to the respective context. Academia's prominent feasibility and technology-oriented mindset (Besterfield et al., 2008) as well as the publicly sponsored project structure in academia (Nicholson \& Ioannidis, 2012) create an environment that lacks market and user/customer centricity. However, we found that facilitators well versed in Design Thinking are able to make all aspects come to force. Unlike in established and organized corporate innovation processes with dedicated innovation and facilitation roles (Tidd and Bessant, 2014), academically led innovation projects often lack a systematic approach to innovation and facilitation.

Our research also broadens the current understanding of the organization of an innovation process and the role and characteristics of an innovation process facilitator. Kolb et al. (2008), Nelson and McFadzean (1998) or Klerkx et al. (2014) mostly view the facilitation tasks they mentioned in the light of the facilitation role in group processes, independent from the setting. Our research contextualizes facilitation in other settings than the industry and goes beyond the project governance and knowledge transfer between academia and industry (Hermans \& Castiaux, 2007; Ii et al., 2018; Todeva, 2013). The project management literature about facilitation topics such as Anantamula (2010) or Bartunek et al. (2007) analyzes hierarchical teams, but does not con- 
sider agile teams, as we found them in the industry driven projects. For the mentioned authors, facilitation tasks, mindset etc. would be the (sole) project manager's responsibility. However, while the project manager's task is to manage the project, it appears central that somebody needs to manage the process and the group interactions in a way that it leads to innovation. We recognize the emerging role of facilitators in academically led innovation projects. Still, this role is not as formalized or homogenous as in an industry context but rather self-imposed by the motivated facilitators that take on an intermediary role of translating between disciplines (Price et al., 2018) and helping the project to focus on all dimensions of innovation.

With our research we extend Johnsson's (2018) characteristics of an innovation facilitator with the toolset of facilitators in different contexts: The facilitators need to have a solid toolset which is agile and adapted to the organization's innovation and management practices. The toolset helps guiding the innovation outcome towards feasibility, desirability and viability while building innovation capability of the project team. Despite the different sectors and contexts, Design Thinking was found to be essential for most facilitators when referring to their toolset. This is interesting because design thinking is described a successful approach for product development and innovation (Brown, 2009), but the effect of applying design thinking is difficult to measure and debated by managers and scholars (Kleinsmann, Valkenburg \& Sluijs, 2017; Liedtka, 2018). Our research opens avenues to extend the ongoing discussion in combination with the facilitation literature.

Our findings also support the particular importance of facilitation in early (set-up) project stages where problems and solution space are more abstract and developing the team's collaboration and innovation skills are most important (Lee \& Sukoco, 2011). This is similar in both contexts, industry and academia.

\subsection{Conclusion and conceptualization of a context-specific facilitation fra- mework}

Our findings point to differences in facilitation efforts and roles due to the different organizational context. We found that the innovation focus at the beginning of innovation projects differs depending on the academic and industrial environment. We developed a chess metaphor to illustrate the context of innovation projects as shown in Figure 3. All innovation projects have the same overarching goal of producing an innovation, so the "innovation game" is the same in all contexts. A central figure is the facilitator in his/her role as a moderator, who must be as flexible and adaptable to changes in the game as the knight in a chess game. The facilitator is responsible for identifying process needs. He/she jumps back and forth between different focal points according to the different project needs. In doing so, he/she uses tools to advance and focus the innovation process. The facilitators in our study usually have a Design Thinking mindset and toolset. They indicate that they give more weight to the user perspective, which is often overlooked in innovation projects. This makes the project result more desirable for the users. The users in our chess metaphor are the most underestimated chess piece, the pawns. However, they play a crucial role in every innovation project. The context is king. Like the king, the context is not flexible, but extremely powerful. It determines the project process and the priorities with its way of thinking. This way of thinking seems to favor only one or two of the 
three innovation characteristics. Therefore, facilitators need to help project teams to consider the other characteristics in order to reach the sweet spot of innovation (Brown, 2009).

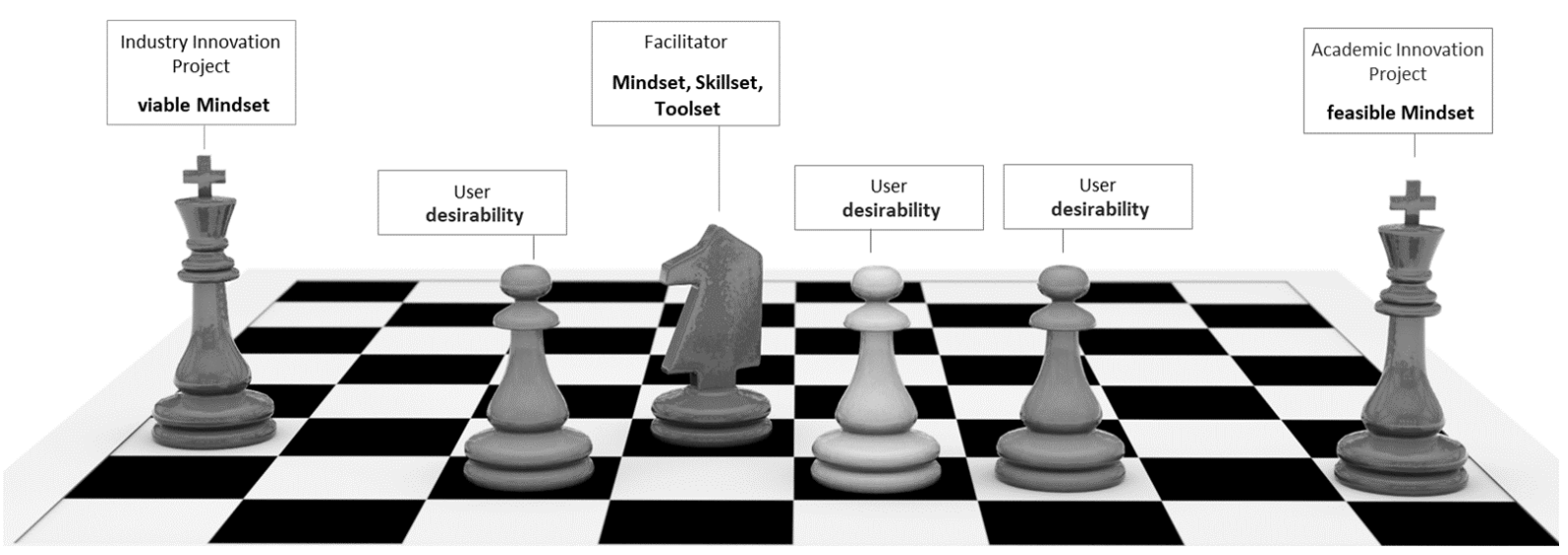

Fig. 3. A metaphor figure illustrating the game of innovation

Although there are active and agile facilitators in both innovation contexts, the rigid project structure and team member's mindset in the academic environment can hinder innovation work. In particular, the project planning phase of an academic innovation project has the potential for more explicit consideration of facilitation in the processes and routines to be defined in advance. Due to the rigid planning, agile reactions to new developments, which may involve changing partners and budgets, are not envisaged (Nicholson \& Ioinnidis, 2012). Here, it is recommended to include budgets for facilitation in the project planning. Industry-driven innovation projects, on the other hand, usually force rigid decision-making processes for or against projects. In certain, defined project phases, however, they are more flexible in terms of time frame, costs and partners. While the administrative burden is higher for academically driven projects, the phases of industry-driven innovation projects may involve more time-consuming decision-making processes to ensure that the project is still viable and marketable.

A very determining factor in the study was the different main objectives of the different sponsors of an innovation project, which also reflects the findings of Simon et al. (2011). The sponsors of academically driven projects focus very strongly on the feasibility of an innovation project, while the sponsors of industrially driven projects are more interested in the feasibility of a possible innovation. In short, academic innovation projects strive to find answers to the questions "how to create" and "what to offer", whereas industry-driven innovation projects aim to find answers to "who to serve" and "how to deliver". This orientation is also reflected in the role of the facilitator. Most industry facilitators see themselves at least partly as consultants, while most academic facilitators perform their role partly as facilitators and partly as researchers.

In academic innovation projects, funding is mainly provided by public institutions that are prohibited by law from benefiting from the innovation. The natural scientists working in the academic institutions are also trained to focus on feasibility, i.e. in particular on technological aspects. They do not exhaustively take into account the aspects of economic efficiency and user-centeredness. The reason for this could be that public financiers cannot finance the actual 
development of new products and services in order to avoid illegal subsidies. While viability is generally not required in a publicly funded institution, a lack of it makes it difficult for private companies that need a viable product or service to finally implement academic research. The currently under-utilized areas of viability and user desirability therefore constitute the potential for innovation in academic research.

The feasibility of the innovation project as well as user requirements are not necessarily at the forefront of the considerations of industry's innovation sponsors. In projects driven by industry, the viability of a possible innovation is the central question for innovation leaders. Market share, profit margin and other business-related aspects are important decision criteria for or against sponsoring an innovation (Dong et al., 2017). Therefore, a primary task of facilitation is to combine the different logics that prevail in different contexts. In order to reconcile the different logics, almost all facilitators used the methodology of Design Thinking, which focuses on people.

By bringing these insights together, we developed the idea that the most important role of a facilitator is to act as a bridgehead to unite the three perspectives from the very beginning of an innovation. The facilitator's way of thinking is therefore crucial for innovation projects. It includes the facilitator's understanding of their function within the process and of the process itself, their role andtheir objectives. This way of thinking is the key factor in driving innovation processes, it reflects the organizational logic and corresponds to the organizational focus. However, it also explicitly includes desirability orientation (user orientation) and, to a certain extent, the orientation that does not appear to be that important for the organization concerned. These ideas are summarized in the following figure.

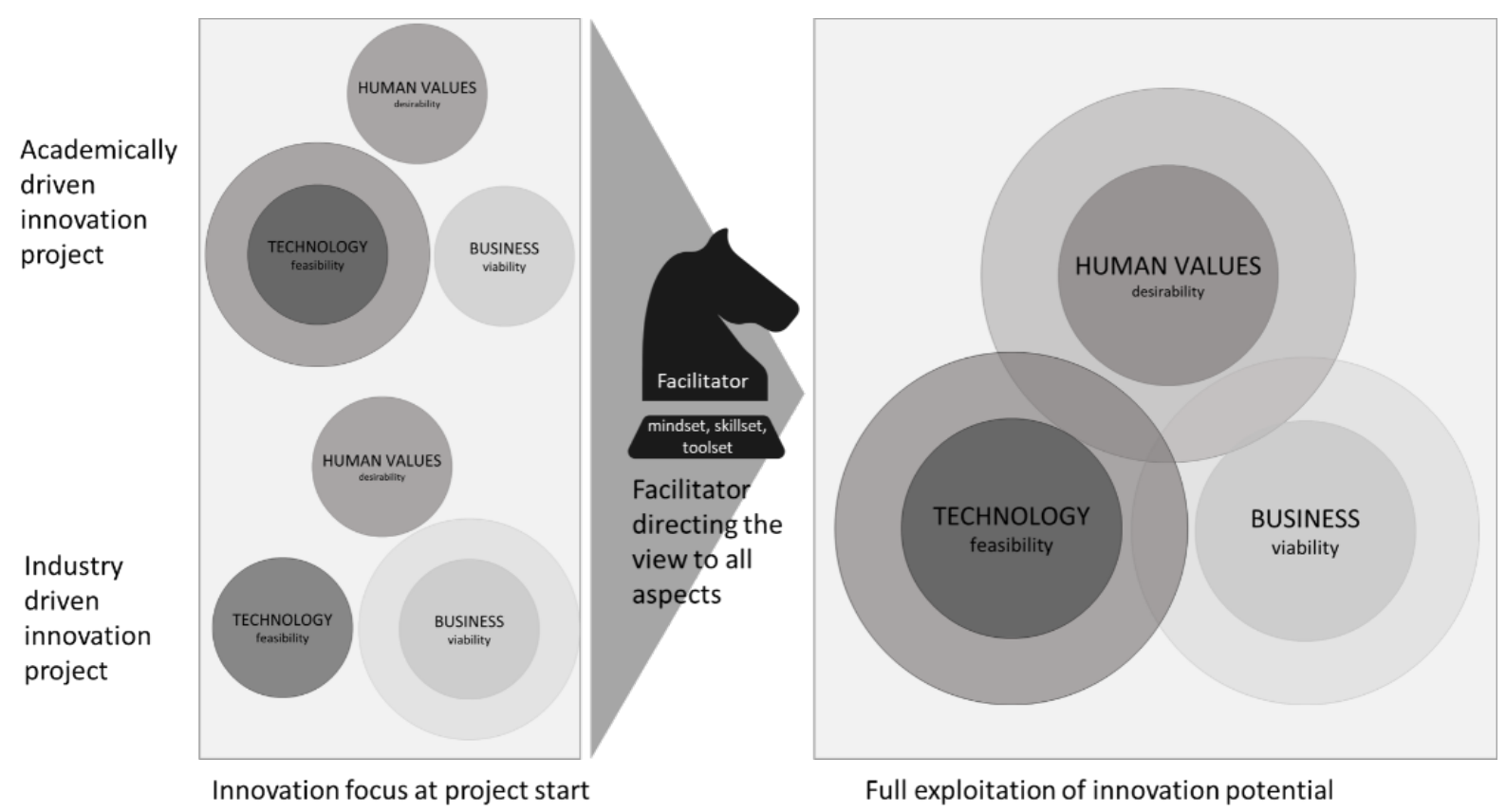

Fig. 4. Conceptualization of the facilitator role in innovation projects 


\subsection{Managerial Implications}

The central practical aspect of this paper is to empower innovation teams to fully exploit the innovation potential by guiding them to the sweet spot of innovation via facilitation. This includes, as we argue, in particular the awareness of the innovation context. For this purpose, the facilitator needs to recognize the different starting conditions in innovation processes and, if necessary, identify and take into account blind spots. This means that context-specific activities are advisable in order to achieve an improved implementation process. It is important to establish an adaptable facilitation for the different perspectives, priorities and different views in an innovation project. Consequently, the facilitators should identify and include missing perspectives and stakeholders (chess players) by moving back and forth between the different participants in the innovation game, like the knight in a chess game. For an overall understanding, we have developed and abstracted the following framework for facilitators and innovation practitioners for this process of reconciling the different perspectives (see Figure 5):

1. Application of tools

At the beginning, the facilitators build on the instruments that already exist or have been proven within an innovation process. The innovation facilitators from our study mainly use Design Thinking tools in both contexts. The use of Design Thinking changes the way innovation projects work to more agile processes and faster iterations. The tools used by facilitators are adapted to the specific conditions of an innovation project. What works well will be maintained in the future. Through the facilitation process, the application practice develops and adapts to the organization, while the organization also continues to evolve as the use of Design Thinking increases.

2. Improve innovation capabilities Secondly, the use of the tools also influences the improvement of the skills of the team members. They learn how to use the tools during their application. This has positive spillover effects on the present and future way of working.

3. Shifting and creating an innovative way of thinking

Thirdly, innovation practitioners must cover the three different perspectives on innovation during the project process in order to exploit the full innovation potential. In short, we develop what we feed: Market share, user-centricity or technical superiority. A truly innovative product or service contains all three values.

Facilitators promote awareness processes regarding the different perspectives on innovation by incorporating into the innovation work tools that the teams use in the project. Rapid experimentation leads to rapid familiarization with concepts of radical user-centricity, such as developing a persona or a customer journey.

The facilitator's work involves questioning the approach in the innovation process and, if necessary, encouraging a rethink towards new ways of thinking.

4. Adapting what works well

Using the tools means acquiring new skills. The introduction and application of the new tools leads to a learning process in the innovation team. The tools have the potential to create a new way of working. A good facilitator senses what works well in the specific 
organizational cultures and adapts his/her tools accordingly. The facilitator supports the learning process of the people involved in the innovation process with reflective questions.

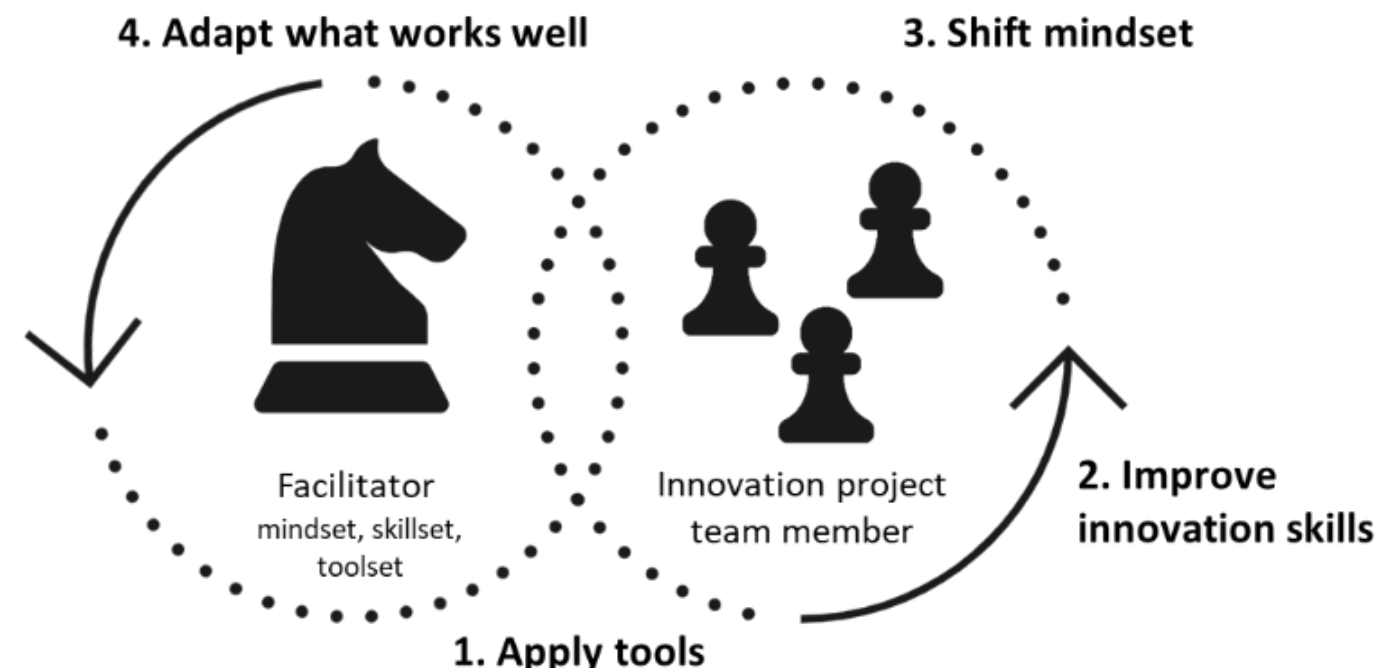

Fig. 5. Facilitation learning cycle

\subsection{Limitations and Further Research}

The results of the study were obtained from nine organizations and are therefore not representative for a generalization. Although we have received some in-depth information and new impulses regarding our understanding of facilitation, the topic should be examined more thoroughly. A quantitative study within the cases described and beyond could contribute to the validation of our results. Particularly interesting in the light of current scholarly and management discourse is the role of Design Thinking in facilitation and its contribution to innovation outcome. Longitudinal studies to find out whether different industrial and academic approaches can produce different outcomes (such as start-ups, number of new innovative products or services) would also be very useful for assessing facilitation strategies. We therefore recommend research that puts these factors into context. In particular, limitations in academically driven, publicly funded innovation projects are an issue in the literature that needs further investigation (e.g. Quélin et al., 2017). Apart from this, extending research to SME-internal innovation projects and the related facilitation and innovation patterns would contribute to the research topic.

\section{Acknowledgements}

We thank the Norwegian Fund for Research Fees for Agricultural Products (FFL) supporting the study through the project "InnoFood" (NRC262303) and the German Federal Ministry of Education and Research (BMBF) with - Entrepreneurial Regions and their initiative "Twenty20" for the support of the research and innovation consortia "3Dsensation" including the "InnoFly3D" pro- 
ject as well as the project "ClusterFeedback", and the Thuringian Ministry for Economic Affairs, Science and Digital Society through the project "Digital Innovation Hub Photonics"

\section{References}

Anantatmula, V. (2010). Project Manager Leadership Role in Improving Project Performance. Engineering Management Journal, 22(1), 13-22.

Autodesk White paper (2017) Toolset, Skillset, Mindset: The three essential elements of innovation. http://labs.blogs.com/innovation/AutodeskInnovationWhitepaper_V16.pdf, accessed March 23, 2020.

Bartunek, J., Trullen, J., Immeadiato, S. \& Schneider, F. (2007). Front and Backstages of the diminished Routinization of Innovations: What Innovation Research finds behind the Scenes. Strategic Entrepreneurship Journal, 1(3-4), 295-314.

Beloniel, P. \& Somech, A. (2015). The Role of Leader Boundary Activitites in Enhancing Inderdisciplinary Team Effectiveness. Small Group Research, 46(I), 83-124.

Bester[FB01?]eld-Sacre, B. L., Golish, M.E., \& Shuman, L. J. (2008). Comparing Academic and Corporate Technology Development Processes. Journal of Product Innovation Management, 25, $47-62$.

Bozic, N. Y. (2016). Integrated model of innovation competence. Paper presented at the 27th ISPIM Innovation Conference, Porto, Portugal, June 2016.

Brenner, W., Uebernickel, F., \& Abrell, T. (2016). Design thinking as mindset, process, and toolbox. In Design thinking for innovation (pp. 3-21). Springer, Cham6

Brown, T. (2008). Design Thinking. Harvard Business Review, June, 84-92.

Brown, T. (2009). Change by design: How Design Thinking transforms organizations and inspires innovation. New York: HarperBusiness.

Brown, T. \& Katz, B. (2011). Change by Design. Journal of Product Innovation Management, 38(3), 381-383.

Brunswicker, S. \& Vanhaverbeke, W. (2015). Open Innovation in Small and Medium-Sized Enterprises (SMEs): External Knowledge Sourcing Strategies and Internal Organizational Facilitators. Journal of Small Business Management, 53(4), 1241-1263.

Cambridge Dictionary. (n.d.). Facilitator. Cambridge University Press. https://dictionary.cambridge.org/dictio accessed March 17, 2020.

Chesbrough, H. (2006). "Open Innovation: A New Paradigm for Understanding Industrial Innovation" in Chesbrough, H., Vanhaverbeke, W. \& West, J. (Eds.): Open Innovation: Researching a New Paradigm. Oxford: Oxford University Press.

Chesbrough, H. (2013). Open business models: How to thrive in the new innovation landscape. Boston: Harvard Business Press. 
Clark, D. (2012). Innovation Management in SMEs: Active Innovators in New Zealand. Journal of Small Business and Entrepreneurship, 23(4), 601-619.

Curedale, R. (2019) Design Thinking Process \& Methods 5th Edition, Design Community College, ISBN:1940805457

Davis, J. P. \& Eisenhardt, K. M. (2011). Rotating Leadership and Collaborative Innovation: Recombination Processes in Symbiotic Relationships. Administrative Science Quarterly, 56(2), 159-201.

Design Council (2007). Eleven lessons: managing design in eleven global companies. https:// www.designcouncil.org.uk/sites/default/files/asset/document/ElevenLessons_DeskResearchReport_ 0.pdf, accessed August 22, 2019.

Djelassi, S. \& Decoopman, I. (2016). Innovation through interactive crowdsourcing: The role of boundary objects. Recherche et Applications en Marketing, 31(3), 131 -152.

Dong, J. Q., McCarthy, K. J. \& Schoenmakers, W. W. M. E. (2017). How Central Is Too Central? Organizing Interorganizational Collaboration Networks for Breakthrough Innovation. Journal of Product Innovation Management, 34(4), 526-542

Eisenhardt, K. (1989). Building theories from case study research. Academy of Management Review, 14(4), 532-550.

European Commission. (2018a). A renewed agenda for research and Innovation.

https://ec.europa.eu/info/publications/renewed-european-agenda-research-and-innovation-europeschance-shap en, accessed March 23, 2020.

European Commission. (2018b). Horizon Dashboard. https://ec.europa.eu/info/funding-tenders/opportunities dashboard, accessed March 23, 2020.

Francis, D. \& Bessant, J. (2005). Targeting innovation and implications for capability development. Technovation, 25(3), 171-183.

Glaser, B. G: \& Strauss, A. L. (1967). The Discovery of Grounded Theory: Strategies for Qualitative Research. Chicago: Aldine Publishing Company.

Gonera, A., \& Pabst, R. (2019). The Use of Design Thinking in Transdisciplinary Research and Innovation Consortia: Challenges, Enablers, and Benefits. Journal of Innovation Management, $7(3), 96-122$.

Hermans, J., \& Castiaux, A. (2007). Knowledge Creation through University-Industry Collaborative Research Projects. Electronic Journal of Knowledge Management, 5(1).

Horth, D.M., Vehar, J. (2012) Becoming a Leader Who Fosters Innovation. White Paper. Center for Creative Leadership. https://www.ccl.org/wp-content/uploads/2014/03/BecomingLeaderFostersInnovation accessed March 23, 2020.

Howard, Z., Senova, M., Melles, G. (2015). Exploring the role of mindset in design thinking: Implications for capability development and practice. Journal of Design, Business \& Society, $1(2), 183-202$ 
Hunter, S. \& Cushenbery, L. (2011). Leading for Innovation: Direct and Indirect Influences. Advances in Developing Human Resources, 13(3), 248 -265.

Ii, S. S., Fitzgerald, L., Morys-Carter, M. M., Davie, N. L., \& Barker, R. (2018). Knowledge translation in tri-sectoral collaborations: An exploration of perceptions of academia, industry and healthcare collaborations in innovation adoption. Health Policy, 122(2), 175-183.

Jiang, Y., \& Chen, C. C. (2016). Integrating Knowledge Activities for Team Innovation: Effects of Transformational Leadership. Journal of Management, 44(5), 1819-1847.

Johnsson, M. (2017). Creating High-performing Innovation Teams. Journal of Innovation Management, 4(4), 24-47.

Johnsson, M. (2018). The innovation facilitator: characteristics and importance for innovation teams. Journal of Innovation Management, 6(2), 12-44.

Kleinsmann, M., Valkenburg, R., \& Sluijs, J. (2017). Capturing the value of design thinking in different innovation practices. International Journal of Design, 11(2), 25-40.

Klerkx, L., Álvarez, R., \& Campusano, R. (2014). The emergence and functioning of innovation intermediaries in maturing innovation systems: the case of Chile. Innovation and Development, 5(1), 73-91.

Kolb, J., Hin, S. \& Song, J. and Ji Hoon Song. (2008). A Model of Small Group Facilitator Competencies. Performance Improvement Quarterly, 21(2), 119-133.

Konsti-Laakso, S., Pihkala, T. \& Kraus, S. (2012). Facilitating SME Innovation Capability through Business Networking. Creativity and Innovation Management, 21(1), 1-13.

Lee, L. T-S. \& Sukoco B. M. (2011). Reflexivity, stress, and unlearning in the new product development team: the moderating effect of procedural justice. R\&D Management, 41 (4), 410-423.

Liedtka, J. (2018), "Why Design Thinking Works", Harvard Business Review. SeptemberOctober, pp. 72-79.

Mazzucato, M. (2018). Mission-oriented research \& innovation in the European Union: A

problem-solving approach to fuel innovation-led growth. https://ec.europa.eu/info/sites/info/ files/mazzucato_report_2018.pdf, accessed March 23, 2020.

Nelson, T. \& McFadzean, E. (1998). Facilitating problem-solving groups: facilitator competences. Leadership \& Organization Development Journal, 19(29), 72-78.

Nelson, H. G., \& Stolterman, E. (2003). The design way: Intentional change in an unpredictable world: Foundations and fundamentals of design competence. Englewood Cliffs, New Jersey: Educational Technology Publications.

Nicholson, J. M., Ioannidis, J. P. (2012). Research grants: Conform and be funded. Nature, $492(7427), 34$.

Ollila, S. \& Yström, A. (2017). An investigation into the roles of open innovation collaboration managers. R\&D Management, 47(2), 236-252. 
Price, R., Wrigley, C. \& Matthews, J. (2018). Action researcher to design innovation catalyst: Building design capability from within. Action Research, June 7, 2018, https://journals.sagepub. com/doi/full/10.1177/1476750318781221\#_i20, accessed August 22, 2019.

Popowitz, M. \& Dorgelo, C. (2018). University-led Grand Challenges. Retrieved from https:

//escholarship.org/uc/item/46f121cr, accessed March 22, 2020.

Quélin, B.V., Kivleniece, I. and Lazzarini, S. (2017) 'Public-Private Collaboration, Hybridity and Social Value: Towards New Theoretical Perspectives', Journal of Management Studies, 54(6), 763-792.

Salazar, M., Lant, T., Fiore, S. \& Salas, E. (2012). Facilitating Innovation in Diverse Science Teams Through Integrative Capacity. Small Group Research, 43(5), 527-558.

Salerno, M. S., Gomes, L. A. de V., Silva, D. O. da, Bagno, R. B., \& Freitas, S. L. T. U. (2015). Innovation processes: Which process for which project? Technovation, 35, 59-70.

Simons, T., A. Gupta and Buchanan, M. (2011). "Innovation in R\&D: Using design thinking to develop new models of inventiveness, productivity and collaboration." Journal of Commercial Biotechnology 17(4), 301-307.

Studioscience. (2017). Design Thinking: mindset, skillset, toolset. https://studioscience.com/ wp-content/uploads/2016/01/DesignThinking_MindsetSkillsetToolset_v1.pdf, accessed March 23, 2020.

The Framework Bank. (2016). A Venn Diagram for Innovation. https://medium.com/@JenBonhomme/avenn-diagram-for-innovation-5097ba91a1c6, accessed March 23, 2020.

Tidd, J., \& Bessant, J. (2014). Strategic innovation management. John Wiley \& Sons.

Thompson, M. A., Owen, S., Lindsay, J. M., Leonard, G. S., \& Cronin, S. J. (2017). Scientist and stakeholder perspectives of transdisciplinary research: Early attitudes, expectations, and tensions. Environmental Science \& Policy, 74, 30-39.

Todeva, E. (2013). Governance of innovation and intermediation in Triple Helix interactions. Industry and higher education, 27(4), 263-278.

Yin, R. K. (2017). Case study research and applications: Design and methods. Los Angeles: Sage publications. 


\section{Biographies}

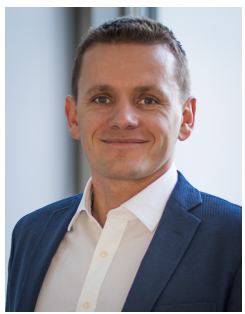

Reinhold Pabst. Reinhold Pabst is a business development manager and researcher in the field of innovation management at the applied research organization Fraunhofer Institute IOF in Germany. He holds a PhD in Innovation Marketing, a M.A. in Coaching and Leadership and a M.Sc. in Business Administration. In his research he focuses on the role of innovation facilitation and the linked competencies and tools. His practical experience includes entrepreneurship in two start-ups and over ten years of coaching and consulting within innovation, business and personnel development.

CRediT Statement: Conceptualization, Methodology, Validation, Formal Analysis, Investigation, Resources, Writing - Original Draft, Writing - Review \& Editing, Visualization, Supervision, Project Administration, Funding Acquisition.

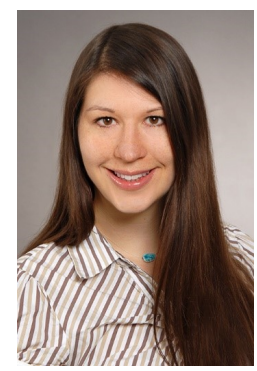

Isabelle Tyrasa. Isabelle Tyrasa works as a $\mathrm{PhD}$ candidate and project manager in the field of Innovation Management at the Fraunhofer Institute for Applied Optics and Precision Engineering. She holds a M.A. of Intercultural Personnel Development and Communication Management. Her main research topics are innovation collaboration and innovation processes. The research projects she works on include crowdsourcing, NPD and agile personnel development.

CRediT Statement: Methodology, Validation, Formal Analysis, Investigation, Data Curation, Writing - Original Draft, Writing - Review \& Editing.

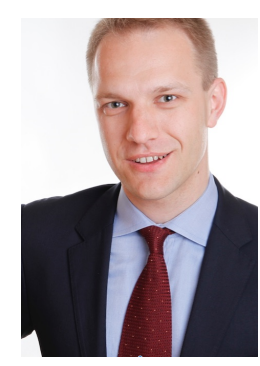

Sebastian G.M. Händschke. Sebastian GM Händschke heads the "Digital Innovation Hub Photonics" at the Fraunhofer Institute for Applied Optics and Precision Engineering IOF in Jena enabling founding intentions in optics and photonics in order to re-enlive the spirit of Zeiss, Abbe, and Schott in the "Optical Valley". He holds a PhD in organization studies with a thesis on knowledge transfer after master studies at the universities of Berkeley and Erfurt as well as at the London School of Economics and Political Science (LSE). His research interests include institutional theory, pluralist approaches to management theories, research-practice bridges in innovation and entrepreneurship as well as the Computational Social Sciences.

CRediT Statement: Conceptualization, Writing - Original Draft, Writing - Review 8 Editing.

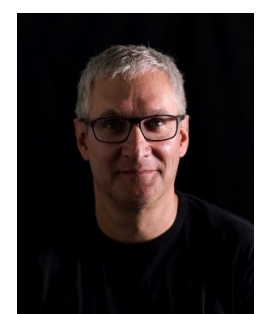

Ralph Siepmann. Ralph Siepmann is Design Thinking Coach and consultant for digital workplace and collaboration at edcom $\mathrm{GmbH}$ in Munich, Germany. He is a strong advocate of self-organized teams and advises organizations on how to build intelligent, practical use cases with a focus on value creation and clear story mapping. His work and research focuses on "strategic foresight", the effort to anticipate future user needs based on history and external trends, influences and developments.

CRediT Statement: Conceptualization, Resources.

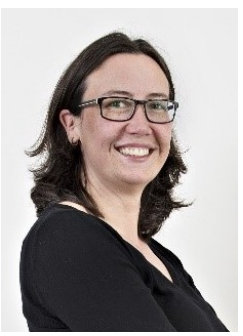

Antje Gonera. Antje Gonera is senior scientist at the Norwegian food research institute NOFIMA in the Department of Sensory, Consumer, and Innovation and leads the strategic research program on innovation in the food industry. She holds a PhD in Food Science and an exec. MBA in Innovation Studies from the Business School in Oslo, Norway. Dr. Gonera previously has had international roles in in the consumer goods industry, biotechnology, and consulting. Her research focus is on the implementation and understanding of the use of design thinking, user focus, and agile innovation methods into transdisciplinary academia-industry research collaborations.

CRediT Statement: Conceptualization, Methodology, Resources, Writing-Original Draft, Writing - Review \& Editing, Visualization.

\section{ISSN 2183-0606}

http://www.open-jim.org

http://creativecommons.org/licenses/by/3.0 